\title{
ANALISA GETARAN AKIBAT KERUSAKAN DEEP GROOVE BALL BEARING SERI 6003RS
}

\author{
Muhamad Riva'i ${ }^{1}$, Nanda Pranandita ${ }^{2}$ \\ ${ }^{1,2}$ Jurusan Teknik Mesin - Politeknik Manufaktur Negeri Bangka Belitung \\ Kawasan Industri Airkantung Sungailiat, \\ Telp.0717-93586, Fax.0717-93585, rivai72djuhari@gmail.com
}

\begin{abstract}
Measurement of the damage of elements in bearing can be by measuring the vibration generated in the form of a frequency signal when the pad is rotating. Measurement of vibration on the bearing by using vibration measuring instrument. Damage to the rolling bearing includes damage to the cage, outer ring, inner ring and balls. The rolling bearings used in this study are deep groove ball bearing type $6003 R S$ with internal diameter $(d)=17 \mathrm{~mm}$, outer diameter $(D)=35 \mathrm{~mm}$, bearing thickness $(B)=$ 10 , number of rolling elements $(\mathrm{Nb})=10$ pieces, and the diameter of the rolling element $(B d)=4.75 \mathrm{~mm}$. In the rotation of the bearing $(\mathrm{Fr})=2003 \mathrm{rpm}(33.38 \mathrm{~Hz})$ we found the experimental results of bearings that have been damaged in the outer race at $138 \mathrm{~Hz}$ frequency, inner race damage at $196 \mathrm{~Hz}$ frequency, (ball) at a frequency of $88.8 \mathrm{~Hz}$ and cage damage at a frequency of $13.8 \mathrm{~Hz}$
\end{abstract}

Keywords: damage, vibration, deep groove ball bearing

\begin{abstract}
Abstrak
Pengukuran kerusakan elemen-elemen pada bantalan gelinding dapat dilakukan dengan mengukur getaran yang ditimbulkan berupa sinyal frekuensi ketika bantalan tersebut berputar. Pengukur getaran pada bantalan dengan menggunakan alat ukur vibrasi. Kerusakan yang terjadi pada bantalalan gelinding meliputi kerusakan pada rangka (cage), ring luar (outer ring), ring dalam (inner ring) dan elemen gelinding (balls). Bantalan gelinding yang digunakan pada penelitian ini tipe deep groove ball bearing nomor seri 6003 RS dengan diameter dalam $(d)=17 \mathrm{~mm}$, diamater luar $(D)=35 \mathrm{~mm}$, tebal bearing $(B)=10$, jumlah elemen gelinding $(\mathrm{Nb})=10$ buah, dan diameter elemen gelinding $(B d)=$ 4,75 mm. Pada putaran bantalan $(\mathrm{Fr})=2003 \mathrm{rpm}(33.38 \mathrm{~Hz})$ didapatkan hasil percobaan terhadap bantalan yang telah mengalami kerusakan pada lintasan luar pada frekuensi $138 \mathrm{~Hz}$, kerusakan lintasan dalam pada frekuensi $196 \mathrm{~Hz}$, kerusakan pada bola bantalan pada frekuensi 88,8 $\mathrm{Hz}$ dan kerusakan pada pemisah pada frekuensi $13,8 \mathrm{~Hz}$.
\end{abstract}

Kata kunci: kerusakan, getaran, deep groove ball bearing

\section{PENDAHULUAN}

Setiap mesin yang menggunakan penggerak motor listrik atau pun motor bakar akan mengalami getaran. Getaran tersebut akan mempengaruhi kinerja dari sebuah mesin. Getaran dapat terjadi dikarenakan beberapa hal seperti miss alignment maupun unbalance. Pada penelitian ini, merupakan pengujian terhadap sebuah alat bantu untuk mengetahui getaran yang diakibatkan kerusakan elemen bantalan. Bantalan gelinding yang digunakan yaitu tipe deep groove ball bearing nomor seri 6003 RS dengan dengan diameter dalam $(d)=17 \mathrm{~mm}$, diamater luar $(D)=35 \mathrm{~mm}$, tebal bearing $(B)=10$, jumlah elemen gelinding $(\mathrm{Nb})=10$ buah, dan diameter elemen gelinding $(\mathrm{Bd})=4,75$ $\mathrm{mm}$. Pada dasarnya sebuah bantalan gelinding diproduksi dengan standar yang tinggi dan material yang terkontrol. Ukuran diameter bola dan roler pada bearing dibuat dengan toleransi 0,001 inchi $(0,00245$ $\mathrm{mm}$ ) atau lebih. Normal bola (ball) dan roler (roller) bearing terdiri dari dua ring baja yang dikeraskan, bola-bola (balls) atau roller bearing dipisahkan oleh rangka (cage) yang berfungsi untuk mengurangi gesekan [1]. Sebagai ilustrasi ditampilkan gambar bagian-bagian dari sebuah bantalan gelinding deep groove ball bearing yang ditunjukkan Gambar 1. 


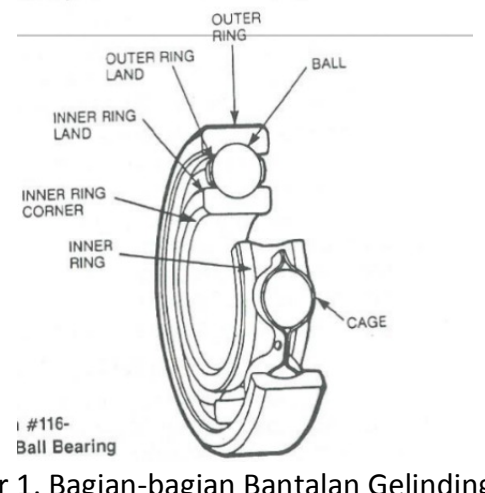

Gambar 1. Bagian-bagian Bantalan Gelinding

Kerusakan pada sebuah bantalan (bearing) dapat diindikasikan dan dianalisis secara visual dengan mata telanjang setelah bantalan dilepas dari sebuah poros atau rumah (housing) bantalan. Ada beberapa kasus kerusakan bearing yang dapat dianalisis dengan secara visual, yakni akibat kelebihan beban, panas yang berlebihan, pemasangan yang salah, kontaminasi, kesalahan pelumas dan lainlainnya. Teknologi mutakhir telah menyediakan alat untuk analisis kerusakan elemen-elemen pada sebuah bearing berdasarkan getaran yang ditimbulkan. Pengukuran getaran yang ditimbulkan oleh sebuah bearing harus dilakukan pada saat mesin beroperasi.

Pengukuran getaran (vibration) pada bearing dapat dilakukan dengan menggunakan vibration test. Kerusakan lokal pada bearing terjadinya terjadi karena adanya impuls getaran pada saat terjadi tumbukan antara elemen yang berputar dengan cacat lokal. Nilai frekuensi impuls yang digunakan tergantung pada letak cacat lokal pada bearing tersebut. Setiap kerusakan yang terjadi pada bearing memiliki frekuensi yang spesifik. Misalnya frekuensi kerusakan pada cage yang disebut dengan istilah Fundamental Train Frequency (FTF) yang besarnya dapat ditentukan dengan teoritis dengan menggunakan persamaan sebagai berikut;

$F T F=\frac{f r}{2} x\left(1-\frac{B d}{P d} x \cos \propto\right)$

Kerusakan pada lintasan dalam (inner race) atau ball pass frequency inner race (BPFI) dapat ditentukan secara teori dengan persamaan berikut dibawah ini $B P F I=\frac{N b}{2} f r\left(1+\frac{B d}{P d} \cos \propto\right)$

Kerusakan pada lintasan luar (outer race) disebut dengan ball pas frequency outer race ( BPFO) yang dinyatakan dalam persamaan sebagai berikut :

$$
B P F O=\frac{N b}{2} f r\left(1-\frac{B d}{P d} \cos \propto\right)
$$

Kerusakan pada elemen gelinding (rolling element) atau disebut juga dengan ball spin frequency (BSF) dapat dihitung dengan persamaan berikut :

$\left.B S F=\frac{N b}{2 \cdot B d}, f r 4\right)$

Keterangan :

$\mathrm{fr} \quad=$ Frekuensi motor $(\mathrm{Hz})$

$\mathrm{Nb} \quad=$ Jumlah bola

$\mathrm{Pd} \quad=$ Diameter picth $(\mathrm{mm})$

$\mathrm{Bd} \quad=$ Diameter bola $(\mathrm{mm})$

$\propto \quad$ = Sudut kontak bola (ㅇ)

Ketika mengidentifikasikan apa penyebab kerusakan sebuah bearing perlu diperhatikan bagaimana pembebanan terhadap bearing dan apakah diterapkan untuk membawa beban. Ketika menganalisis getaran yang terjadi pada daerah bantalan (bearing) yang menjadi dugaan permasalahan, jangan langsung menghilangkan kemungkinan penyebab-penyebab yang lainnnya seperti 
ketidakseimbangan (unbalance), ketidaksumbuan poros (misalignment) dan pemasangan bearing setelah ada penggantian [2].

\section{METODE PENELITIAN}

\subsection{TAHAPAN PENELITIAN} Gambar 2.

Langkah-langkah yang dilakukan dalam penelitian ini disajikan dalam diagram alir pada

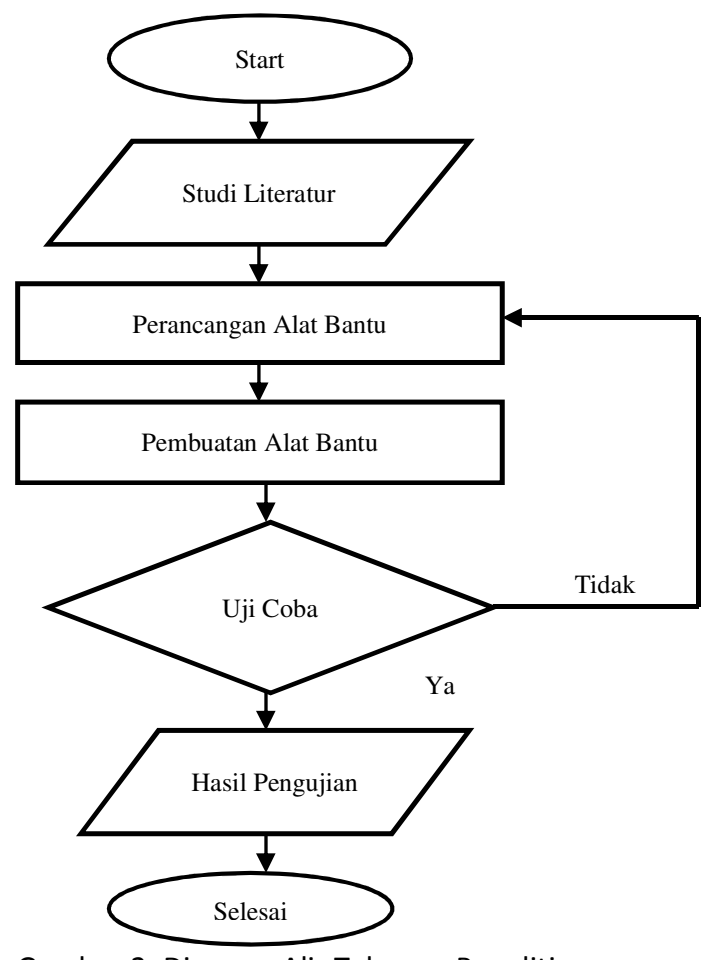

Gambar 2. Diagram Alir Tahapan Penelitian

\subsection{PERANCANGAN DAN PEMBUATAN ALAT BANTU}

Pada penelitian ini, dibuat media/alat bantu yang akan digunakan sebagai media pengujian kerusakan bearing yang ditunjukkan pada Gambar 3.

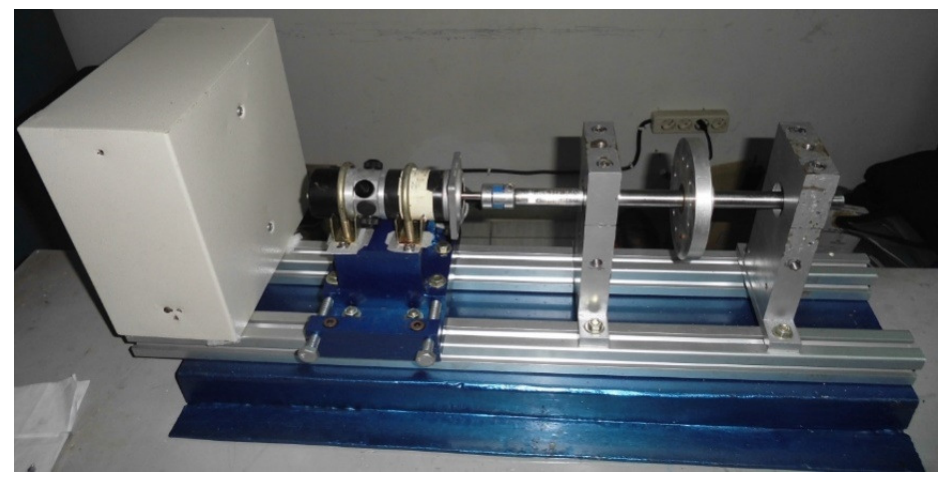

Gambar 3. Alat Bantu Pengujian 
Data teknis bearing yang digunakan pada pengujian adalah sebagai berikut:

Nomor seri bantalan : $6003 \mathrm{RS}$

Tipe bantalan : Deep groove ball bearing

Diameter luar (Do) : : $35 \mathrm{~mm}$

Diameter dalam (Di) $\quad: 17 \mathrm{~mm}$

Diameter pitch (Pd) : $26 \mathrm{~mm}$

Jumlah bola $(\mathrm{Nb}) \quad: 10$

Diameter bola $(\mathrm{Bd}) \quad: 4,75 \mathrm{~mm}$

Sudut kontak $(\alpha) \quad: 0^{\circ}$

Data-data teknis bantalan yang digunakan pada percobaan ini merujuk dari katalog yang dikeluarkan oleh pabrik bantalan SKF

\section{$2.3 \quad$ UJI COBA}

Sebelum percobaan dapat dilakukan, alat bantu pengujian yang dibuat harus dapat dipastikan kesejajarannya (alignment) dan kesetimbangannya (balance). Setelah kedua proses tersebut dilaksanakan maka dapat dilanjutkan dengan uji coba pengukuran getaran yang timbul pada posisi vertikal dan horizontal dengan beberapa jenis cacat elemen pada bearing. Putaran yang digunakan sebesar 2003 rpm (33,38 Hz). Pengukuran getaran yang terjadi terhadap bearing mulai dari kerusakan cage, outer race, inner race, dan ball bearing ditunjukkan pada Gambar 4 s.d Gambar 7.

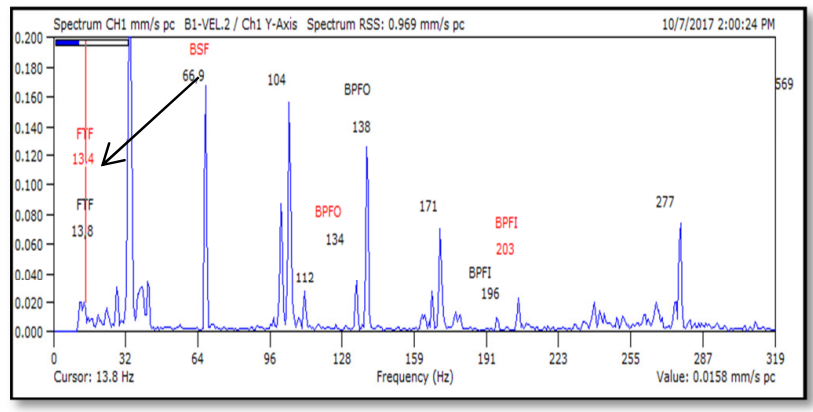

Gambar 4. Getaran Akibat Kerusakan pada Cage

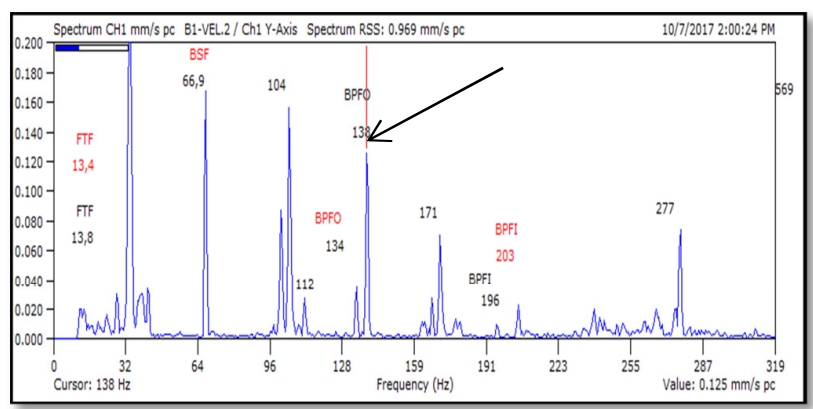

Gambar 5. Getaran Akibat Kerusakan pada Outer Race 


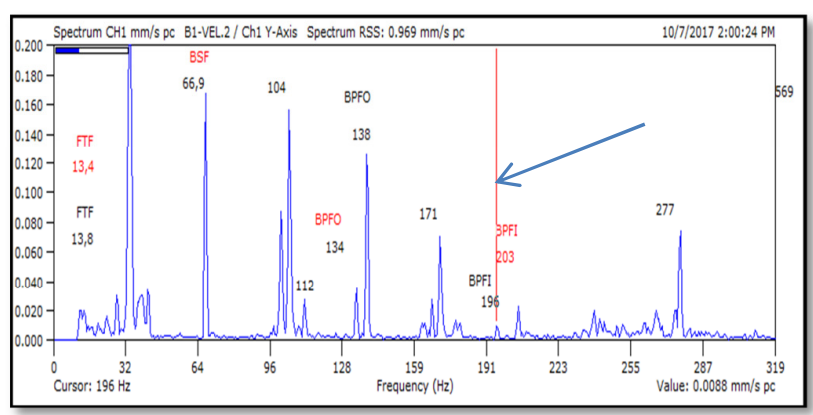

Gambar 6. Getaran Akibat Kerusakan pada Inner Race

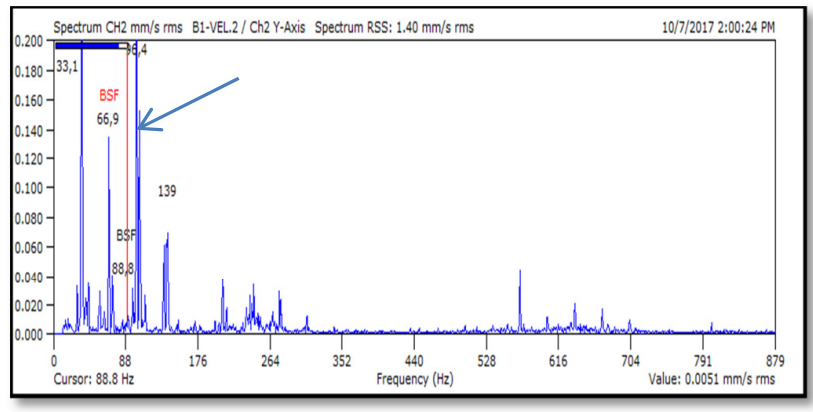

Gambar 7. Getaran Akibat Kerusakan pada Ball Bearing

\section{HASIL DAN PEMBAHASAN}

Berdasarkan hasil uji coba, frekuensi spesifik kerusakan pada bearing dihitung secara teoritik, yang ditampilkan pada Tabel 1.

Tabel 1. Data Perhitungan Teoritik Spesifik Kerusakan Elemen Bearing

\begin{tabular}{ccc}
\hline Putaran $(\mathbf{H z})$ & Jenis Kerusakan & Hasil Perhitungan (Hz) \\
\hline \hline \multirow{3}{*}{33,38} & FTF & 13,64 \\
\cline { 2 - 3 } & BSF & 88,31 \\
\cline { 2 - 3 } & BPFO & 136,41 \\
\hline
\end{tabular}

\section{SIMPULAN}

Berdasarkan hasil pengukuran dapat diketahui bahwa pada putaran bantalan $(\mathrm{Fr})=2003 \mathrm{rpm}$ ( $33.38 \mathrm{~Hz}$ ) didapatkan hasil percobaan terhadap bantalan yang telah mengalami kerusakan pada lintasan luar (outer race) di frekuensi $138 \mathrm{~Hz}$, kerusakan lintasan dalam (inner race) di frekuensi $196 \mathrm{~Hz}$, kerusakan pada bola bantalan (ball) di frekuensi $88,8 \mathrm{~Hz}$ dan kerusakan pada pemisah (cage) pada frekuensi $13,8 \mathrm{~Hz}$

\section{DAFTAR PUSTAKA}

[1]. B. M. Basaraba and J. A. Archer, Power Transmission System, 11th ed., Canada: IPT Publishing and Training Ltd., 2011.

[2]. B. M. Basaraba and J. A. Archer, Machinery Reability and Condition Monitoring, 4th ed., Canada: IPT Publishing and Training Ltd., 2006.

[3] T.-J. Lin and et al, "Finite Element Analysis for Dynamic Characteristic of a Deep-Groove Ball Bearing in Motion Process," Journal of Vibration and Shock, vol. 1, no. 1, p. 028, 2009 